\title{
Inhibitors targeting the SUMOylation pathway: A patent review 2012-2015 (Review)
}

\author{
YANJUN ZHOU $^{1}$, CHUNMEI JI ${ }^{1}$, MENGDA CAO ${ }^{1}$, MIAO GUO ${ }^{1}$, WEN HUANG ${ }^{1}$, \\ WEIWEI NI ${ }^{1}$, LING MENG ${ }^{1}$, HAIWEI YANG ${ }^{2}$ and JI-FU WEI ${ }^{1}$ \\ ${ }^{1}$ Research Division of Clinical Pharmacology; ${ }^{2}$ Department of Urology, \\ Jiangsu Province People's Hospital, Nanjing, Jiangsu 210029, P.R. China
}

Received March 10, 2016; Accepted October 27, 2017

DOI: $10.3892 /$ ijmm.2017.3231

\begin{abstract}
Small ubiquitin-related modifier (SUMO) proteins bind to the lysine residue of target proteins to produce functionally mature proteins. The abnormal SUMOylation of certain target proteins is associated with diseases including cancer, heart disease, diabetes, arthritis, degenerative diseases and brain ischemia/stroke. Thus, there has been growing appreciation for the potential importance of the SUMO conjugation pathway as a target for treating these diseases. This review introduces the important steps in the reversible SUMOylation pathway. The SUMO inhibitors disclosed in the patents between 2012 and 2015 are divided into different categories according to their mechanisms of action. Certain compounds disclosed in this review have also been reported in other articles for their inhibition of the SUMOylation pathway following screening in cell lines. Although there are few studies using animal models or clinical trials that have used these compounds, the application of bortezomin, a ubiquitylation inhibitor, for treating cancer indicates that SUMO inhibitors may be clinically successful.
\end{abstract}

\section{Contents}

1. Introduction

2. Category 1: SUMO mimics

3. Category 2: SUMO enzymes inhibitors

Correspondence to: Dr Ji-Fu Wei, Research Division of Clinical Pharmacology, Jiangsu Province People's Hospital, 300 Guangzhou Road, Gulou District, Nanjing, Jiangsu 210029, P.R. China

E-mail:weijifu@hotmail.com

Mrs. Haiwei Yang, Department of Urology, Jiangsu Province People's Hospital, 300 Guangzhou Road, Gulou District, Nanjing, Jiangsu 210029, P.R. China

E-mail: hwyang2002@163.com

Key words: small ubiquitin-related modifier mimics, SUMOylation enzyme inhibitors, sentrin-specific protease inhibitors, anticancer drugs
4. Category 3: SENP inhibitors

5. Discussion

\section{Introduction}

Precursor proteins are not active, and thus, need further processing to become functional mature proteins. Post-translational protein modification is the chemical modification of proteins prior to or following protein biosynthesis, and includes phosphorylation, ubiquitylation, methylation, acetylation, and modifications by ubiquitin-like modifiers (Ubls).

Ubiquitin ( $\mathrm{Ub}$ ) is a globular protein consisting of 76 amino acid residues, and the UPS (ubiquitin-proteasome system) is responsible for degrading $80-90 \%$ of intracellular proteins. $\mathrm{Ub}$ binds the lysine residues of target proteins by a series of enzymes including the ubiquitin-activating enzyme E1, ubiquitin-conjugating enzyme E2 and the ubiquitin E3 ligases. Subsequently, these ubiquitylated proteins are recognized and degraded by the $26 \mathrm{~S}$ proteasome. Modifications by Ubls are similar to ubiquitylation and they compete for the lysine residues of certain substrates (1).

Small ubiquitin-related modifier (SUMO) proteins are one type of Ubls. Although they only have $~ 18 \%$ sequence identity with ubiquitin, they share a common three-dimensional structure; namely, a globular $\beta$-grasp fold and a characteristic C-terminal diglycine (Gly-Gly) motif that is exposed following maturation (2). SUMOs have a flexible, 20 amino acid N-terminus that seems to primarily serve as an acceptor in the formation of poly-SUMO chains (2). Mammalian cells express four SUMO isoforms: SUMO-1, SUMO-2, SUMO-3 and SUMO-4. SUMO1-3 is ubiquitously expressed in human tissues, whereas SUMO4 is only expressed in the kidney, lymph nodes and spleen (3). SUMO-2 and 3 are 95\% identical to each other and only 50\% identical to SUMO-1 (4); it is not yet clear whether these three isoforms are functionally distinct (6). Unlike SUMO-1, SUMO-2 and 3 have internal SUMO modification sites at their N-termini (K11), which can form poly-SUMO chains (5). The expression level and activity of SUMO proteins affect their conjugation to substrates, although it remains unknown if SUMO-4 can be conjugated to cellular proteins. Similar to the ubiquitylation pathway, 


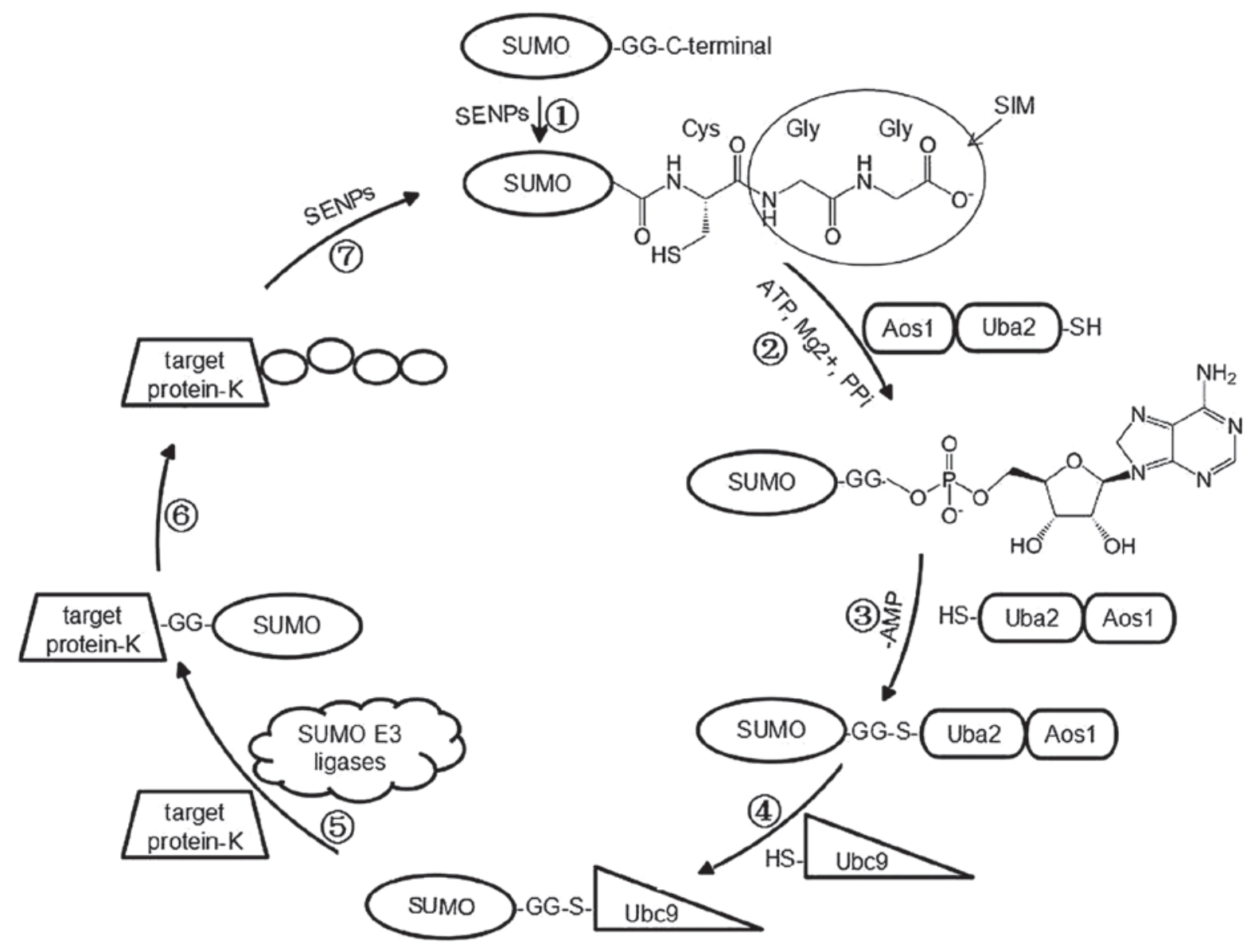

Figure 1. Major steps in the SUMOylation pathway. SENPs cleave the C-terminus of SUMO to expose the Gly-Gly motif required for conjugation, which is also called the SUMO-interacting motif. SAE activates SUMO in a two-step reaction that involves ATP hydrolysis. SAE1 (Aos1) promotes adenylation of the SUMO C-terminus to form the SUMO-AMP intermediate, followed by transfer of SUMO to SAE2 (Uba2) and thioester bond formation. Then SUMO is transferred from SAE to Ubc9. Ubc9 catalyzes formation of an isopeptide bond between the C-terminal glycine of SUMO and a lysine residue in the substrate, usually together with a specific SUMO E3 ligase. Finally, SUMO is removed from the lysine residues of target proteins by SENPS using their isopeptidase activities. SUMO, small ubiquitin-related modifier; SENPs, sentrin-specific proteases; SAE, SUMO-activating enzyme; Aos1, SUMO1 activating enzyme subunit 1; Uba2, ubiquitin like modifier activating enzyme 2; ATP, adenosine triphosphate; AMP, adenosine monophosphate; Ubc9, ubiquitin conjugating enzyme E2.

SUMO conjugation is reversible and catalyzed by a three-step enzymatic reaction that includes activation, conjugation, and ligation (Fig. 1), which does not result in protein decomposition, but rather, in the regulation of normal cell functions such as protein-protein interactions, subcellular localization, DNA repair, and cell cycle and transcription factor regulation (6).

In SUMOylation, initially, sentrin-specific proteases (SENPs) cleave the C-terminus of SUMO using their endopeptidase activities to expose the Gly-Gly motif required for conjugation, which is also termed the SUMO-interacting motif (SIM) (7-9). SENPs have six isoforms (SENP1, 2, 3, 5, 6 and 7) in mammals, which are divided into three subfamilies based on their sequence homology, substrate specificity, and subcellular localization (10). The catalytic cysteine protease domain at the $\mathrm{C}$-terminus is $\sim 250$ amino acid residues in length, and controls the specificity and function of SENP isoforms (11). The catalytic domain crystal structures of SENP1, SENP2 and SENP7, which are comprised of the typical catalytic triad (Cys-His-Asp), are very similar (10). SENP1 and SENP2 have SUMO maturation and deSUMOylation abilities, whereas the other SENPs are unable to induce maturation and prefer SUMO-2/3 over SUMO-1 for deSUMOylation $(10,12)$.
In the second step, SUMO-activating enzyme (SAE) activates the C-terminus of SUMO in a two-step reaction that involves ATP hydrolysis. There is only one heterodimeric E1 enzyme [SAE1/SAE2, also termed activator of SUMO1 (Aos1)/ubiquitin like modifier activating enzyme 2 (Uba2)] involved in the SUMOylation pathway. SAE1 (Aos1) promotes adenylation of the SUMO C-terminus to form the SUMO-adenosine monophosphate (AMP) intermediate, followed by transfer of SUMO to the catalytic Cys173 residue on SAE2 (Uba2) and thioester bond formation (13).

The third step is conjugation. Specifically, SUMO is transferred from SAE to SUMO E2 (also termed ubiquitin conjugating enzyme 2I, UBE2I or Ubc9), again resulting in formation of a thioester linkage between the C-terminal glycine in SUMO and the active site Cys93 residue in Ubc9. Ubc9 is the only known SUMO-conjugating enzyme required for SUMOylation, and its deletion abolishes SUMO conjugation (14).

The fourth step is ligation. Ubc9 catalyzes formation of an isopeptide bond between the C-terminal glycine of SUMO and a lysine residue in the substrate, usually together with a specific SUMO E3 ligase, which increases the efficiency of 
Table I. Summary of compounds included in the patents reviewed.

\begin{tabular}{|c|c|c|c|}
\hline No. & Patent ID & Invention & Mechanism \\
\hline 2.1 & US0302815 & AuNP-ligand conjugates & SIM mimic \\
\hline 3.1 & EP2402334 & MLN4924 & AMP mimic \\
\hline 3.2 & WO002994 & Heteroaryl compounds & SAE inhibitor \\
\hline \multirow[t]{2}{*}{3.3} & US0317101 & MLS-0437113 etc. & Singleton SAE/Ubc9 inhibitor \\
\hline & WO064898 & & \\
\hline \multirow[t]{3}{*}{3.4} & WO064897 & MLS-0207587 etc. & Tricyclic SAE/Ubc9 inhibitor \\
\hline & US0245032 & & \\
\hline & US9045483 & & \\
\hline \multirow[t]{2}{*}{3.5} & EP2545935 & HLS5 polypeptide & Degenerating Ubc9/PIAS1 \\
\hline & US0330738 & & \\
\hline \multirow[t]{2}{*}{4.1} & WO064887 & NSC5068 etc. & SENP1, 2 and 7 inhibitor \\
\hline & US0302525 & & \\
\hline 4.2 & CN104436196 & shRNA & SENP1 inhibitor \\
\hline 4.3 & CN103961348 & Agents for treating prostate cancer & SENP1 inhibitor \\
\hline 4.4 & CN103877078 & Agents for treating breast cancer & SENP2 inhibitor \\
\hline
\end{tabular}

AuNP, gold nanoparticle; SIM, SUMO-interacting motif; AMP, adenosine monophosphate; SAE, SUMO-activating enzyme; Ubc9, ubiquitin conjugating enzyme E2; HLS5, hemopoietic lineage switch 5; PIAS1, protein inhibitor of activated STAT-1; shRNA, short hairpin RNA; SENP, sentrin-specific protease.

this reaction by associating with both the substrate protein and Ubc9 (2,15). Specific E3 ligases in mammals include the protein inhibitor of activated STAT-1 (PIAS) protein family (PIAS1, PIAS3, PIASx $\alpha$, PIASx $\beta$ and PIASy), the nucleoporin Ran binding protein 2 and the human polycomb protein Pc2 (2). The tripartite motif family was recently described as a fourth group of SUMO E3 ligases (16).

In the last step, SUMO is removed from the lysine residues of target proteins by SENPs using their isopeptidase activities (10). Ubiquitin-specific protease-like 1 was identified as a new SUMO isopeptidase, with roles in Cajal body functions (17). DeSUMOylating isopeptidase 1 is another SUMO isopeptidase, which recognizes different sets of substrates to SENPs (18).

All SUMOylation proteins are associated with cancer, as elevated levels of SAE, Ubc9, SUMO E3s and SENPs have been observed in various types of cancer (12,14-16). As target proteins of SUMOylation, the Ras-related nuclear protein GTPase-activating protein (RanGAPl), the nuclear factor- $\kappa \mathrm{B}$ regulatory inhibitor- $\alpha$, the tumor suppressor gene $\mathrm{p} 53$, the androgen receptor, the progesterone receptor and certain other substrates have been reported (19). The abnormal SUMOylation of these target proteins is also associated with heart disease, diabetes, arthritis, degenerative diseases, and brain ischemia/stroke (6). Thus, there has been growing appreciation for the potential importance of the SUMO conjugation pathway as a target for treating these diseases (20-25).

This review discusses the compounds that inhibit the SUMOylation pathway referred to in patents written in English or Chinese (Table I). These compounds can be divided into four categories according to their mechanisms of action. Category 1 compounds are SUMO mimics that can affect the entire pathway. Category 2 comprises SAE and Ubc9 inhibitors, because all SUMO isoforms are activated and conjugated by SAE and Ubc9. Category 3 compounds are ligation inhibitors because of the specificity of SUMO E3 ligases to target proteins. Category 4 compounds are SENP inhibitors that may inhibit maturation and deSUMOylation.

\section{Category 1: SUMO mimics}

Multivalent poly-Ubl chain inhibitors (US0302815) (26)

Structure. Multivalent poly-SUMO chain inhibitors comprise gold nanoparticle (AuNP)-ligand conjugates and include at least two components: AuNPs and modified SIM mimics (26). The basic structures (formula 1 and 2) of SIM mimics and potential compound 1 are shown in Fig. 2 (26). The thiol tail $\left[\mathrm{R}_{3}=-\mathrm{SH}\right.$ or $\left.\mathrm{SH}-\left(\mathrm{CH}_{2}\right)_{2}-\mathrm{CO}-\mathrm{NH}-\right]$ allows the modified SIM mimic to be conjugated to an AuNP by disulfide bonds (26).

Mechanism. The SIM mimic may recapitulate the action of SUMO in protein modification to inhibit the SUMOylation pathway by: i) Forming thioester conjugates with SAE; ii) being transferred from SAE to Ubc9; and iii) being further transferred to the SUMOylation target protein. Once the mimics are conjugated to SAE and Ubc9, they block full-length SUMO from entering the cascade composed of SAE and Ubc9. Thus, SUMO mimics can function as mechanism-based inhibitors of the protein SUMOylation reaction (27). SUMO-2 and 3 are distinct from SUMO-1 in that they harbor internal SUMO modification sites at their N-termini to form poly-SUMO chains (5). Therefore, the conjugation of a weak SUMO-2/3 ligand to AuNPs promotes selective multivalent interactions with poly-SUMO-2/3 chains, resulting in the efficient inhibition of poly-SUMO-chain-mediated protein-protein interactions (5). Metals with high atomic numbers, such as gold, preferentially 
A<smiles>[R3]c1ccc(/C=C/C(=O)NC([R7])C(=O)N[C@@H]([R2])C(=O)O)cc1</smiles>

B<smiles>[R3]c1ccc(COC(=O)NC([R])C(=O)N[C@@H]([R2])C(=O)O)cc1</smiles>

formula 2<smiles>CCC(C)C(NC(=O)/C=C/c1ccc(NC(=O)CCS)cc1)C(=O)N[C@@H](CC(C)C)C(=O)O</smiles>

Figure 2. SIM mimics disclosed in US0302815. (A) Basic structure of the SIM mimics (formula 1); (B) another basic structure of the SIM mimics (formula 2); (C) compound 1 which is derived from the formula 1. SIM, small ubiquitin-related modifier-interacting motif.

absorb more X-ray energy than soft tissues, thus augmenting the effects of ionizing radiation when delivered to cells $(28,29)$.

Application. Multivalent poly-SUMO chain inhibitors can kill cancer cells by increasing radiation sensitivity, while sparing normal cells (26). Thus, these inhibitors provide a viable approach for treating cancer by enhancing the effects of ionizing radiation therapy, which is commonly used in cancer treatment. Combining the properties of nanomaterials with nanoparticles as platforms for multivalent interactions creates important potential therapeutic applications (30).

\section{Category 2: SUMO enzyme inhibitors}

Activating E1 inhibitors (EP2402334) (31)

Structure. There are 86 compounds disclosed in EP2402334, of which most are 4-substituted [(1S,2S,4R)-2hydroxy-4-\{7H-pyrrolo(2,3-d)pyrimidin-7-yl\}cyclopentyl)] methyl sulfamates (formula 3; Fig. 3) (31).

Mechanism. The E1 inhibitors described herein are selective and preferably target human NEDD8-activating enzyme (NAE), SAE, or ubiquitin-activating enzyme, with the most preference for NAE (31). The disclosed SAE inhibitors can also be referred to as AMP mimics; they directly bind to SAE1 and inhibit formation of the SAE-SUMO intermediate. MLS 4924 (compound 3; Fig. 3), an AMP mimic, is a selective and highly potent inhibitor of NAE, and also inhibits SAE with a half maximal inhibitory concentration $\left(\mathrm{IC}_{50}\right)$ value of 8.2 (32).

Application. SAE inhibitors are useful for treating disorders, particularly cell proliferation disorders, including cancer (not limited to solid tumors and hematological tumors), inflammatory and neurodegenerative disorders, and inflammation associated with infection and cachexia (31).

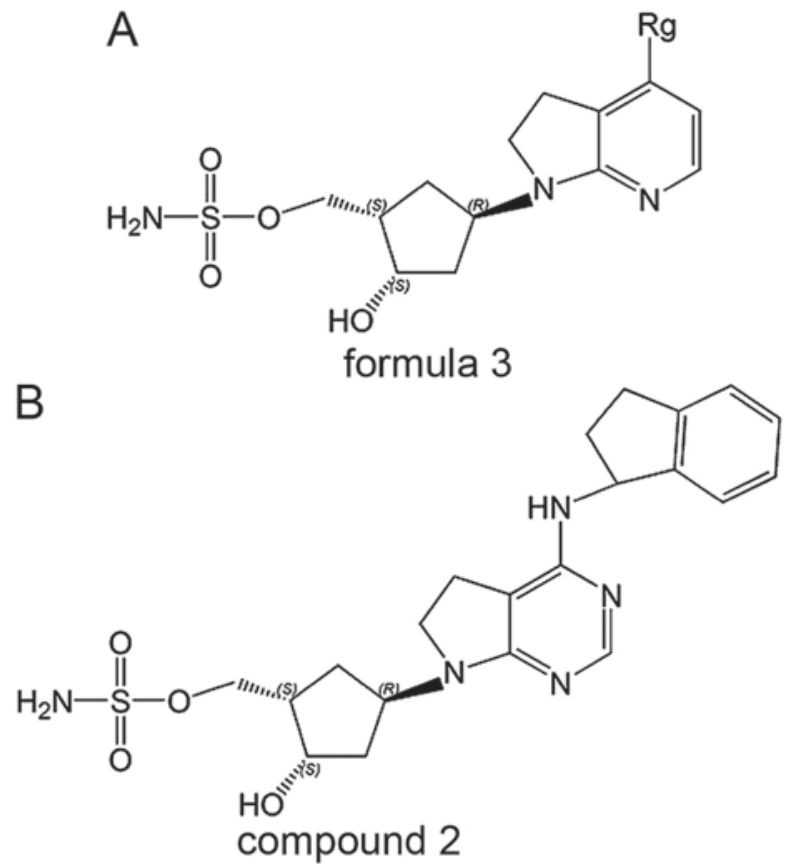

Figure 3. Activating E1 enzyme inhibitors disclosed in EP2042334. (A) Basic structure of the E1 inhibitors (formula 3); (B) compound 2 based on the formula 3 which is called MLN4924 in this patent.

Structure. The basic structure (formula 4) of heteroaryl compounds is shown in Fig. 4. The -Y- is often replaced by -O-, -X1- is often replaced by $-\mathrm{N}-,-\mathrm{X} 2$ - is often replaced by $-\mathrm{N}-$ or $-\mathrm{CH}-$, $\mathrm{Ra}$ can be $-\mathrm{OH}$ or $-\mathrm{F}$ or $-\mathrm{H}$, and $\mathrm{Rc}$ is often replaced by -H. I-1 (compound 4; Fig. 4) and I-5 (compound 5; Fig. 4) are two examples of these heteroaryl compounds (33).

Mechanism. These heteroaryl compounds may be useful as SAE inhibitors (33).

Application. Heteroaryl compounds can be used for the treatment of proliferative, inflammatory, cardiovascular and neurodegenerative disorders (33). The altered expression of proteins in the SAE pathway have been noted in a variety of cancer types including multiple myeloma (MM) (34) and breast cancer (21). In addition, preclinical studies have indicated that Myc-driven cancers may be especially sensitive to SAE inhibition (35).

Singleton inhibitors [US0317101 (36) and WO064898 (37)]

Structure. The structure (formula 5) of singleton inhibitors is presented in Fig. $5(36,37)$.

Mechanism. Singleton inhibitors inhibit the function of SAE and/or Ubc9. MLS-0437113 (compound 5; Fig. 4) is the lead and most potent compound in this series, and strongly inhibits SUMO-RanGap1 and Ubc9 conjugation $(36,37)$. MLS-0417120 (compound 6; Fig. 4) is another potential inhibitor $(36,37)$. There are $16 \mathrm{SAE}$-specific inhibitors in these two patents. MLS-0437317 (compound 7; Fig. 5) is a representative SAE-specific inhibitor that can bind to SAE with high affinity and specificity, and inhibits global SUMOylation in a dose-dependent manner (36,37).

Application. Singleton inhibitors have toxicity in cancer and other diseases by sensitizing cells to genotoxic treatments. Chemoradiotherapy (CRT) is frequently used as a preoperative treatment for colorectal cancer to facilitate surgical 


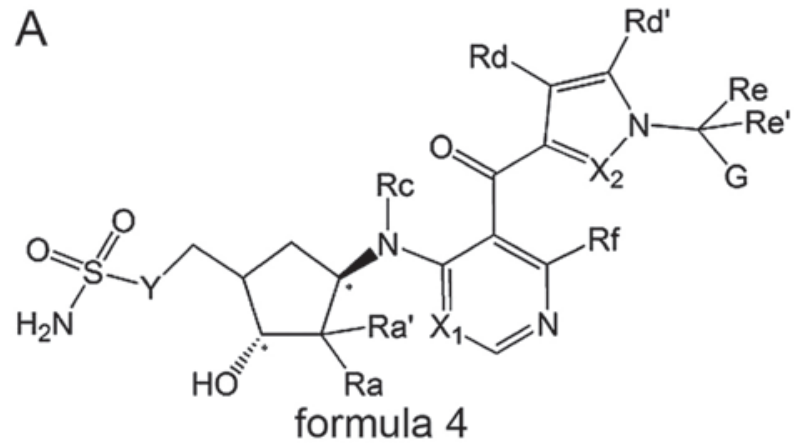<smiles>[B]OC(=O)OCCCCO</smiles><smiles>CCOC(=O)OO[C@H]1[C@@H](O)[C@@H](COS(N)(=O)=O)C[C@H]1Nc1ncncc1C(=O)c1ccn(CC2=CCOCC2)c1</smiles>

Figure 4. Heteroaryl SAE inhibitors disclosed in WO002994. (A) Basic structure of the heteroaryl SAE inhibitors (formula 4); (B) compound 3 derived from the formula 4 which is called I-1 in the patent; (C) compound 4 derived from the formula 4 which is called I-5 in the patent. SAE, small ubiquitin-related modifier-activating enzyme.

intervention and improve long-term survival $(38,39)$. Novel SAE inhibitors can enhance the effects of CRT and/or impair tumor viability, improving treatment outcomes, preserving quality of life and reducing healthcare costs (37). Such inhibitors may be similarly useful in other cancer types (16), diseases, and conditions associated with the overexpression of SAE or Ubc9 $(36,37)$.

Bicyclic and tricyclic inhibitors [WO064897 (40), US0245032 (41) and US9045483 (42)]

Structure. The basic structure in these three patents is formula 6 (Fig. 6). Most tricyclic inhibitors disclosed herein are derived from formulas 7, 8 and 9 (Fig. 6). There are 13 tricyclic SAE inhibitors disclosed in these patents. Compound 8 (Fig. 5)

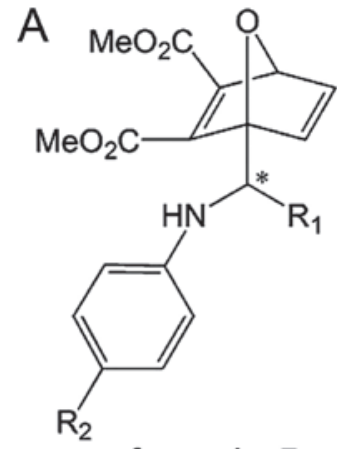

formula 5

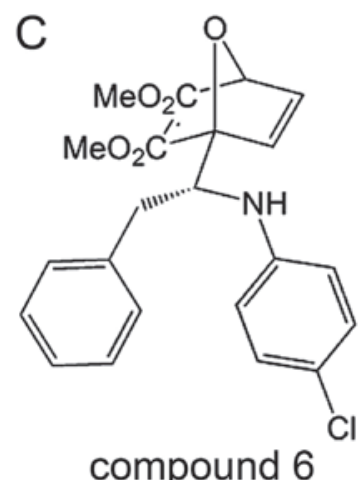

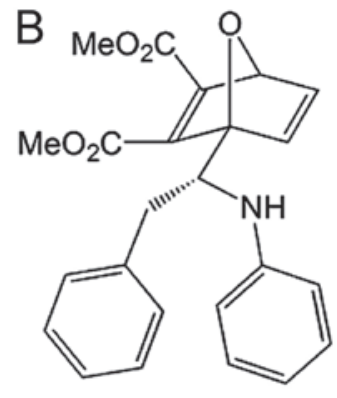

compound 5

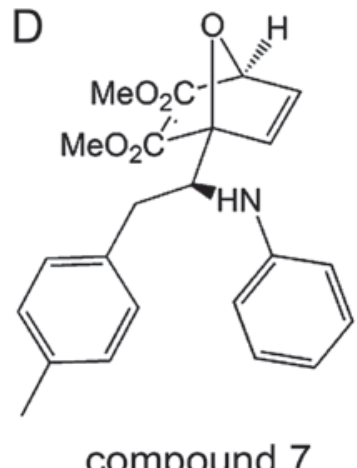

Figure 5. Singleton SAE or Ubc9 inhibitors disclosed in US0317101 and WO064898. (A) Basic structure of the singleton inhibitors (formula 5); (B) compound 5 derived from the formula 5, termed MLS0437113 in these two patents; (C) compound 6 derived from the formula 5, termed MLS0417120 in these two patents; (D) compound 7 derived from the formula 5, termed MLS0437317 in these two patents as a representative SAE-specific inhibitor. SAE, small ubiquitin-related modifier-activating enzyme; Ubc9, ubiquitin conjugating enzyme E2.

is similar to MLS-0207587 (compound 9; Fig. 6), which also showed an $\mathrm{IC}_{50}$ of $0.5 \mu \mathrm{M}(40-42)$.

Mechanism. The tricyclic inhibitors competitively inhibit ATP binding, sensitizing cells to genotoxic stress and inhibiting HIV infection. Some compounds also inhibit Ubc9 (40-42).

Application. These inhibitors can be used to treat cancer, degenerative diseases, and viral infections (e.g. HIV). The characterized tricyclic SAE inhibitors may also induce significant sensitivity to radiation in various cancer cell lines (40-42).

Hemopoietic lineage switch 5 polypeptide [EP2545935 (43) and US0330738 (44)]

Structure. Hemopoietic lineage switch 5 (HLS5) is a member of the RING finger B-box coiled-coil protein family. The gene is located on chromosome $8 \mathrm{p} 21$, a region implicated in numerous leukemias and solid tumors (45). The overexpression of HLS5 in HeLa cells inhibited cell growth, clonogenicity, and tumorigenicity; thus, it is conceivable that HLS5 is a tumor suppressor protein (46).

Mechanism. HLS5 binds SUMO-1 and is SUMOylated in vivo. It also binds Ubc9 and PIAS1, and has a global effect on SUMOylation by causing the degradation of PIAS1 and Ubc9 through its coiled-coil domain $(43,44)$. In addition, HLS5 also increases the SUMOylation of some proteins. It is possible that the effects of HLS5 are concentration-dependent, in that it may promote greater cell death at higher concentrations (47). 
A<smiles></smiles>

formula 6

C<smiles>[R2]Nc1c([SH]([R])=O)c2nc3ccccc3nc2n1[R1]</smiles>

formula 8

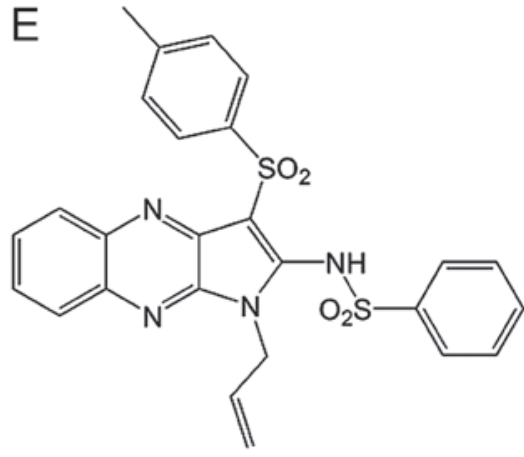

compound 8<smiles>[R9]Nc1c(C=C)c2nc3ccccc3nc2n1CCC</smiles>

formula 7<smiles>[R]Nc1c(C([R])=O)c2nc3ccccc3nc2n1CC</smiles>

formula 9

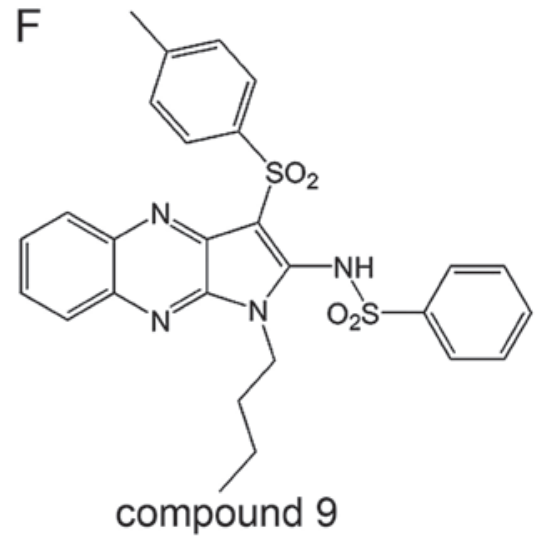

Figure 6. Tricyclic SAE or Ubc9 inhibitors disclosed in WO064897, US0245032 and US9045483. (A) Basic structure of all the compounds disclosed in these three patents (formula 6); (B) basic structure disclosed in US9045483 (formula 7); (C) basic structure disclosed in US9045483 (formula 8); (D) basic structure disclosed in US9045483 (formula 9); (E) compound 8 derived from the formula 8 which is named compound 14 in US9045483; (F) compound 9 derived from the formula 8 which is called MLS0207587 in the former two patents or named compound 13 in US9045483. SAE, small ubiquitin-related modifier-activating enzyme; Ubc9, ubiquitin conjugating enzyme E2.

Application. Ligation inhibitors can be used to treat diseases such as Parkinson's disease, diabetes, Huntington's disease, familial neuronal intranuclear inclusion disease, Alzheimer's disease, neuronal intranuclear inclusion disease, cancer (48-52), polyglutamine disease and human immunodeficiency virus (HIV) infection $(43,44)$.

\section{Category 3: SENP inhibitors}

Inhibitors of deSUMOylation enzymes [WO064887 (53) and US0302525 (54)]

Structure. Compounds 10-11 in Fig. 7 are derived from formula 10 and compounds 12-13 are derived from formula $11(53,54)$. They inhibit SENPs and also inhibit HIV infection (55).

Mechanism. SENPs share a conserved catalytic domain that is a cysteine protease of 225 amino acids (11). Nuclear magnetic resonance and enzyme kinetics data indicate that SENP inhibitors bind in the vicinity of the catalytic center and inhibit the enzyme by a mixed inhibitory mechanism (56). The catalytic domain crystal structures of SENP1, SENP2 and SENP7 are very similar (10). As a result, the inhibitors disclosed herein mostly inhibit SENP1, SENP2 and SENP7.
Application. The SENP inhibitors may sensitize target cells/cancer cells to DNA-damaging therapy, and then minimize or eliminate harm to healthy cells at reduced doses. Inhibitors of deSUMOylation significantly reduce viral infectivity, and limit maintenance of the latent HIV reservoir, which may be valuable to future HIV eradication strategies (57). The SENP inhibitors described herein may also be used to treat cardiovascular disease, neurodegenerative diseases and diabetes in a preventative manner $(53,54)$.

An SENP1 inhibitor: small hairpin RNA [shRNA; CN 104436196 (58)]

Structure. The sequence of the shRNA described herein is 5'-CCGGGCGCCAGAUUGAAGAACAGAACUCGAGUUC UGUUCUUCAAUCUGGCGCUUUUU-3' (SEQ ID no:1) (58).

Mechanism. The SENP1 inhibitor described herein is an shRNA, including the shRNA recombinant vector and host cells containing the recombinant vector (58). As a precursor of small interfering RNA, shRNA can inhibit expression of the SENP1 protein via the RNA interference mechanism, leading to inhibition of cell proliferation and induction of apoptosis of malignant tumor cells (58). 
A<smiles>[R]N=Nc1ccc(-c2ccc(N=N[R7])cc2)cc1</smiles>

formula 10

D<smiles>[R2]N=Nc1ccc(-c2ccc(N=NN[R])cc2S(=O)(=O)O)c(S(=O)(=O)O)c1</smiles>

formula 11
B<smiles>Nc1ccc2cc(S(=O)(=O)O)ccc2c1N=Nc1ccc(-c2ccc(N=Nc3c(N)c(S(=O)(=O)O)cc4cc(S(=O)(=O)O)ccc34)cc2)cc1</smiles>

compound 10

E<smiles>Nc1ccc2ccccc2c1N=Nc1ccc(-c2ccc(N=Nc3c(N)ccc4ccccc34)cc2S(=O)(=O)O)c(S(=O)(=O)O)c1</smiles>

compound 12
C<smiles>Nc1c(N=Nc2ccc(-c3ccc(/N=N/c4cc(S(=O)(=O)O)c5ccccc5c4N)cc3)cc2)cc(S(=O)(=O)O)c2ccccc12</smiles>

F<smiles>CCCCNc1ccc(N=Nc2ccc(-c3ccc(N=Nc4ccc(N)c5ccc(S(=O)(=O)O)cc45)cc3S(=O)(=O)O)c(S(=O)(=O)O)c2)c2cc(S(=O)(=O)O)ccc12</smiles>

Figure 7. SENP1, 2 and 7 inhibitors disclosed in WO064887 and US0302525. (A) Basic structure of the SENPs inhibitors (formula 10); (B) compound 10 derived from the formula 10 which is called NSC16224 in these two patents; (C) compound 11 derived from the formula 10 which is called NSC8676 in these two patents; (D) a basic structure of the SENPs inhibitors (formula 11); (E) compound 12 derived from the formula 11 which is called NSC5068 in these two patents; (F) compound 13 derived from the formula 11 which is called NSC34933 in these two patents. SENP, sentrin-specific protease.

Application. The SENP1 inhibitors described herein can be used for the preparation of certain special agents that can prevent or treat malignant hematological tumors, and those that inhibit the proliferation of malignant hematological tumor cells and/or promote apoptosis in malignant hematological tumor cells (58).

\section{SENP1 inhibitors [CN 103961348 (59)]}

Structure. These SENP1 inhibitors were derived from formula 12 and 13 in Fig. 8 (59), of which the representatives are 2-(4-chlorophenyl)-2-oxoethyl 4-benzamidobenzoate derivatives (60).
Mechanism. The compounds in this patent inhibited the activity of SENP1 in vitro and certain cloned prostate cancer strains (59). Compounds 14 and 15 (Fig. 8) have been reported to have $\mathrm{IC}_{50}$ values of 2.38 and $1.08 \mu \mathrm{M}$, respectively (10).

Application. SENP1 affects the function of hypoxia-inducible factor $1 \alpha$ in tumor angiogenesis, thus promoting the development of various tumors (61). The SENP1 inhibitors described herein can inhibit the growth of prostate cancer cells stimulated by androgen (62-64). Thus, these inhibitors may be useful candidate anticancer drugs. 
A<smiles>[R]c1ccc(C(=O)COC(=O)c2ccc(NC(=O)c3cccc(Cl)c3)cc2)c([R])c1[R]</smiles>

formula 12<smiles>[R]C(=O)Nc1ccc(C(=O)OCC(=O)c2ccc(Cl)cc2)cc1</smiles>

formula 13<smiles>COc1cccc(C(=O)Nc2ccc(C(=O)OCC(=O)c3ccc(Cl)cc3)cc2)c1</smiles><smiles>O=C(COC(=O)c1ccc(NC(=O)c2cccc(OCc3ccccc3)c2)cc1)c1ccc(Cl)cc1</smiles>

Figure 8. SENP1 inhibitors disclosed in CN103961348. (A) Basic structure of the SENP1 inhibitors (formula 12); (B) another basic structure of the SENP1 inhibitors (formula 13); (C) compound 14 derived from the formula 13 which is named 06-036 in this patent; (D) compound 15 derived from the formula 13 which is named 06-197 in this patent. SENP1, sentrin-specific protease 1.

Structure. These inhibitors comprise SENP2 inhibitors containing formula 14 (Fig. 9) as an active ingredient, including its pharmacological derivatives or acceptable salts. This patent has 864 compounds derived from formula 14, differing in $\mathrm{Z}$, $\mathrm{Y}, \mathrm{R}, \mathrm{R} 1$ and R2, compounds 16 and 17 are used here as two examples (65).

Mechanism. The SENP2 inhibitors described have high efficiency and low toxicity, and significantly inhibit SENP2 activity in vitro (65).

Application. The inhibitors of SENP2 described herein can be used to treat breast cancer. By removing the SUMO modification of $\mathrm{Pc} 2$ in the protein regulator of cytokinesis 1 protein, the regulation of polycomb group target gene activity is achieved. SENP2 is involved in the regulation of cell differentiation and development, and is highly expressed in a large number of patients with breast cancer (65). Thus, SENP2 inhibitors may be novel drug candidates for anticancer therapy.

\section{Discussion}

The proteasome inhibitors, bortezomib and carfizomib, which target the ubiquitin pathway, have been used for the treatment of MM and hematologic malignancies (66). The second-generation proteasome inhibitor, carfizomib, induces<smiles>[R]C(=O)Nc1[Y]:[Z](C(=O)OCC(=O)c2ccc([R2])c([R2])c2)ccc1</smiles>

formula 14<smiles>O=C(COC(=O)c1ccc(NC(=O)c2ccccc2)nc1)c1ccc(Cl)cc1</smiles>

compound 16<smiles>CC(=O)OOC(C)OC(=O)OCC(=O)c1ccc(Cl)cc1</smiles>

Figure 9. SENP2 inhibitors disclosed in CN103877078. (A) Basic structure of the SENP2 inhibitors (formula 14); (B) compound 16 which is called 6-002 in this patent; (C) compound 17 which is called 6-006 in this patent. SENP2, sentrin-specific protease 2.

responses in a minority of patients with MM that relapsed from or were refractory to bortezomib treatment, and experienced dose-limiting peripheral neuropathy. However, carfizomib still results in some adverse reactions that are commonly shared with other antineoplastic agents. To identify more effective agents with less toxicity, inhibitors targeting the SUMOylation pathway have been investigated.

This review summarizes compounds inhibiting the SUMOylation pathway that were described in patents written in English or Chinese between 2012 and 2015. Among these compounds, SAE and SENP1/2 inhibitors appear to have the greatest therapeutic potential, as once protein maturation or activation is blocked, downstream biological events will be inhibited. However, SAE, Ubc9 and SENP1/2 inhibitors do not have target selectivity, whereas SUMO E3 ligases inhibitors may be more selective with fewer side effects.

Research studies should not just focus on SUMO inhibitors, but should also take SUMO activators, such as cysteine protease polypeptides, into consideration (67-70). These proteins function as SENPs, with the ability to cleave SUMO from a target protein and/or cleave the precursor form of SUMO to release its active form. These SENP analogs (cysteine protease polypeptides) may be useful in the treatment of various cancers and some other diseases related to cysteine family members (71). PIAS1 is a breast cancer suppressor protein (72). An artificial SUMO ligase reportedly promotes the process of ligation (73).

The application of SUMO inhibitors for treating cancer is of utmost importance. Thus, additional studies should focus on identifying the roles of SUMO enzymes in different cancer 
types. In addition, an understanding of the basic biology and specificity/selectivity of SUMO inhibitors is required before they can be identified and developed for use in the clinic. Although, to date, no SUMO inhibitors have been tested in humans, and further experiments are required in cells and animals, compounds targeting the SUMOylation pathway may represent a new direction for the treatment of cancer and other diseases.

\section{Acknowledgements}

This study was sponsored by the grants from the National Natural Science Foundation of China (grant no. 81571568); the Jiangsu Province's Key Provincial Talents Program (grant no. RC201170); the Priority Academic Program Development of Jiangsu Higher Education Institutions (PAPD); the Six Talents Peak projects of Jiangsu Province (to J.-F.W. and H.Y.).

\section{References}

1. Herrmann J, Lerman LO and Lerman A: Ubiquitin and ubiquitin-like proteins in protein regulation. Circ Res 100: 1276-1291, 2007.

2. Flotho A and Melchior F: Sumoylation: A regulatory protein modification in health and disease. Annu Rev Biochem 82 : 357-385, 2013.

3. Bohren KM, Nadkarni V, Song JH, Gabbay KH and Owerbach D: A M55V polymorphism in a novel SUMO gene (SUMO-4) differentially activates heat shock transcription factors and is associated with susceptibility to type I diabetes mellitus. J Biol Chem 279: 27233-27238, 2004.

4. Geiss-Friedlander R and Melchior F: Concepts in sumoylation: A decade on. Nat Rev Mol Cell Biol 8: 947-956, 2007.

5. Tatham MH, Jaffray E, Vaughan OA, Desterro JM, Botting $\mathrm{CH}$, Naismith JH and Hay RT: Polymeric chains of SUMO-2 and SUMO-3 are conjugated to protein substrates by SAE1/SAE2 and Ubc9. J Biol Chem 276: 35368-35374, 2001.

6. Yang W and Paschen W: SUMO proteomics to decipher the SUMO-modified proteome regulated by various diseases. Proteomics 15: 1181-1191, 2015.

7. Hannich JT, Lewis A, Kroetz MB, Li SJ, Heide H, Emili A and Hochstrasser M: Defining the SUMO-modified proteome by multiple approaches in Saccharomyces cerevisiae. J Biol Chem 280: 4102-4110, 2005.

8. Hecker CM, Rabiller M, Haglund K, Bayer P and Dikic I: Specification of SUMO1- and SUMO2-interacting motifs. J Biol Chem 281: 16117-16127, 2006.

9. Song J, Durrin LK, Wilkinson TA, Krontiris TG and Chen Y: Identification of a SUMO-binding motif that recognizes SUMO-modified proteins. Proc Natl Acad Sci USA 101: 14373-14378, 2004.

10. Kumar A and Zhang KY: Advances in the development of SUMO specific protease (SENP) inhibitors. Comput Struct Biotechnol J 13: 204-211, 2015.

11. Hickey CM, Wilson NR and Hochstrasser M: Function and regulation of SUMO proteases. Nat Rev Mol Cell Biol 13: 755-766, 2012.

12. Bettermann K, Benesch $\mathrm{M}$, Weis $\mathrm{S}$ and Haybaeck $\mathrm{J}$ : SUMOylation in carcinogenesis. Cancer Lett 316: 113-125, 2012.

13. Olsen SK, Capili AD, Lu X, Tan DS and Lima CD: Active site remodelling accompanies thioester bond formation in the SUMO E1. Nature 463: 906-912, 2010.

14. Kumar A, Ito A, Hirohama M, Yoshida M and Zhang KY: Identification of sumoylation inhibitors targeting a predicted pocket in Ubc9. J Chem Inf Model 54: 2784-2793, 2014.

15. Kumar A, Ito A, Hirohama M, Yoshida M and Zhang KY: Identification of sumoylation activating enzyme 1 inhibitors by structure-based virtual screening. J Chem Inf Model 53 : 809-820, 2013

16. Mattoscio D and Chiocca S: SUMO pathway components as possible cancer biomarkers. Future Oncol 11: 1599-1610, 2015.
17. Schulz S, Chachami G, Kozaczkiewicz L, Winter U, Stankovic-Valentin N, Haas P, Hofmann K, Urlaub H, Ovaa H, Wittbrodt $\mathrm{J}$, et al: Ubiquitin-specific protease-like 1 (USPL1) is a SUMO isopeptidase with essential, non-catalytic functions. EMBO Rep 13: 930-938, 2012.

18. Shin EJ, Shin HM, Nam E, Kim WS, Kim JH, Oh BH and Yun Y: DeSUMOylating isopeptidase: A second class of SUMO protease. EMBO Rep 13: 339-346, 2012.

19. Shirong L and Wei H: Sumoylation - a muitffunctional post-translational protein modification. J Med Mol Biol 3: 212-215, 2006

20. Liu X, Xu Y, Pang Z, Guo F, Qin Q, Yin T, Sang Y, Feng C, Li X, Jiang L, et al: Knockdown of SUMO-activating enzyme subunit 2 (SAE2) suppresses cancer malignancy and enhances chemotherapy sensitivity in small cell lung cancer. J Hematol Oncol 8: 67, 2015.

21. Chen SF, Gong C, Luo M, Yao HR, Zeng YJ and Su FX: Ubc9 expression predicts chemoresistance in breast cancer. Chin J Cancer 30: 638-644, 2011.

22. Rabellino A, Carter B, Konstantinidou G, Wu SY, Rimessi A, Byers LA, Heymach JV, Girard L, Chiang CM, Teruya-Feldstein J, et al: The SUMO E3-ligase PIAS1 regulates the tumor suppressor PML and its oncogenic counterpart PML-RARA. Cancer Res 72: 2275-2284, 2012.

23. Li T, Huang S, Dong M, Gui Y and Wu D: Prognostic impact of SUMO-specific protease 1 (SENP1) in prostate cancer patients undergoing radical prostatectomy. Urol Oncol 31: 1539-1545, 2013.

24. Bossis G, Sarry JE, Kifagi C, Ristic M, Saland E, Vergez F, Salem T, Boutzen H, Baik H, Brockly F, et al: The ROS/SUMO axis contributes to the response of acute myeloid leukemia cells to chemotherapeutic drugs. Cell Rep 7: 1815-1823, 2014.

25. Dassouki Z, Sahin U, El Hajj H, Jollivet F, Kfoury Y, Lallemand-Breitenbach $\mathrm{V}$, Hermine $\mathrm{O}$, de Thé $\mathrm{H}$ and Bazarbachi A: ATL response to arsenic/interferon therapy is triggered by SUMO/PML/RNF4-dependent Tax degradation. Blood 125: 474-482, 2015.

26. Chen Y, Horne D, Li YJ, Ma LY, Perkins-Harki AL and Su Y: Multi-valent poly-ubl chain inhibitors and methods of use. US Patent 0302815. Filed February 21, 2012; issued August 5, 2014.

27. Zhao B, Villhauer EB, Bhuripanyo K, Kiyokawa H, Schindelin H and Yin J: SUMO-mimicking peptides inhibiting protein SUMOylation. Chembiochem 15: 2662-2666, 2014.

28. Butterworth KT, Coulter JA, Jain S, Forker J, McMahon SJ, Schettino G, Prise KM, Currell FJ and Hirst DG: Evaluation of cytotoxicity and radiation enhancement using $1.9 \mathrm{~nm}$ gold particles: Potential application for cancer therapy. Nanotechnology 21: 295101, 2010.

29. Li YJ, Perkins AL, Su Y, Ma Y, Colson L, Horne DA and Chen Y: Gold nanoparticles as a platform for creating a multivalent poly-SUMO chain inhibitor that also augments ionizing radiation. Proc Natl Acad Sci USA 109: 4092-4097, 2012.

30. Chithrani DB, Jelveh S, Jalali F, van Prooijen M, Allen C, Bristow RG, Hill RP and Jaffray DA: Gold nanoparticles as radiation sensitizers in cancer therapy. Radiat Res 173: 719-728, 2010.

31. Langston SP, Olhava EJ and Vyskocil S: Inhibitors of E1 activating enzymes. EP Patent 2402334 A1. Filed February 2, 2006; issued Junuary 26, 2012

32. Soucy TA, Smith PG, Milhollen MA, Berger AJ, Gavin JM, Adhikari S, Brownell JE, Burke KE, Cardin DP, Critchley S, et al: An inhibitor of NEDD8-activating enzyme as a new approach to treat cancer. Nature 458: 732-736, 2009.

33. Diffey MO, England DB, Hu ZG, Ito M, Langston SP, Mcintyre C, Mizutani $\mathrm{H}$ and $\mathrm{Xu} \mathrm{H}$ : Heteroaryl compounds useful as inhibitors of SUMO activating enzyme. WO Patent 2015002994 A2. Filed July 1, 2014; issued January 8,2015

34. Driscoll JJ, Pelluru D, Lefkimmiatis K, Fulciniti M, Prabhala RH, Greipp PR, Barlogie B, Tai YT, Anderson KC, Shaughnessy JD Jr, et al: The sumoylation pathway is dysregulated in multiple myeloma and is associated with adverse patient outcome. Blood 115: 2827-2834, 2010.

35. Kessler JD, Kahle KT, Sun T, Meerbrey KL, Schlabach MR, Schmitt EM, Skinner SO, Xu Q, Li MZ, Hartman ZC, et al: A SUMOylation-dependent transcriptional subprogram is required for Myc-driven tumorigenesis. Science 335: 348-353, 2012. 
36. Chen Y, Li YJ, Divlianska D, Bobkova E and Roth G: Singleton inhibitors of SUMOylation enzymes and methods for their use. US Patent 20130317101 A1. Filed May 9, 2013; issued November 28, 2013.

37. Chen Y and Li YJ: Singleton inhibitors of SUMOylation enzymes and methods for their use. WO Patent 064898 A1. Filed May 9 2013; issued January 19, 2016.

38. Maas M, Nelemans PJ, Valentini V, Crane CH, Capirci C, Rödel C, Nash GM, Kuo LJ, Glynne-Jones R, García-Aguilar J, et al: Adjuvant chemotherapy in rectal cancer: Defining subgroups who may benefit after neoadjuvant chemoradiation and resection: A pooled analysis of 3,313 patients. Int J Cancer 137: 212-220, 2015.

39. García-Aguilar J, Hernandez de Anda E, Sirivongs P, Lee SH, Madoff RD and Rothenberger DA: A pathologic complete response to preoperative chemoradiation is associated with lower local recurrence and improved survival in rectal cancer patients treated by mesorectal excision. Dis Colon Rectum 46: 298-304, 2003.

40. Chen Y and Li YJ: Bicyclic and tricyclic inhibitors of SUMOylation enzymes and methods for their use. WO Patent 064897 A2. Filed November 9, 2011; issued May 18, 2012.

41. Chen Y, Li YJ, Divlianska D, Bobkova E, Roth G, Jun PU and Khan P: Bicyclic and tricyclic inhibitors of SUMOylation enzymes and methods for their use. US Patent 20130245032 A1 Filed May 9, 2013; issued September 19, 2013.

42. Chen Y, Li YJ, Divlianska D, Bobkova E, Roth G, Jun PU and Khan P: Inhibitors of small ubiquitin-like modifier enzymes with substituted pyrrolo(2,3-B)quinoxalines. US Patent 9045483 B2. Filed May 9, 2013; issued June 2, 2015.

43. Lalonde JP, Lim R, Scaife R, Gallagher S and Klinken SP: HLS-5, a control SUMOylation agent. EP Patent 2545935 A1. Filed October 6, 2006; issued January 16, 2013.

44. Klinken SP, Lalonde JP, Lim R, Scaife R and Gallagher S: SUMOylation control agent and uses thereof. US Patent 20130330738 A1. Filed Junuary 4, 2013; issued December 12 , 2013.

45. Knuutila S, Aalto Y, Autio K, Björkqvist AM, El-Rifai W, Hemmer S, Huhta T, Kettunen E, Kiuru-Kuhlefelt S, Larramendy ML, et al: DNA copy number losses in human neoplasms. Am J Pathol 155: 683-694, 1999.

46. Lalonde JP, Lim R, Ingley E, Tilbrook PA, Thompson MJ, McCulloch R, Beaumont JG, Wicking C, Eyre HJ, Sutherland GR, et al: HLS5, a novel RBCC (ring finger, B box, coiled-coil) family member isolated from a hemopoietic lineage switch, is a candidate tumor suppressor. J Biol Chem 279: 8181-8189, 2004.

47. Kimura F, Suzu S, Nakamura Y, Nakata Y, Yamada M, Kuwada N, Matsumura T, Yamashita T, Ikeda T, Sato K, et al: Cloning and characterization of a novel RING-B-box-coiled-coil protein with apoptotic function. J Biol Chem 278: 25046-25054, 2003.

48. Alshareeda AT, Negm OH, Green AR, Nolan C, Tighe P, Albarakati N, Sultana R, Madhusudan S, Ellis IO and Rakha EA: SUMOylation proteins in breast cancer. Breast Cancer Res Treat 144: 519-530, 2014

49. Coppola D, Parikh V, Boulware D and Blanck G: Substantially reduced expression of PIAS1 is associated with colon cancer development. J Cancer Res Clin Oncol 135: 1287-1291, 2009.

50. Chen P, Zhao D, Sun Y, Huang L, Zhang S and Yuan Y: Protein inhibitor of activated STAT-1 is downregulated in gastric cance tissue and involved in cell metastasis. Oncol Rep 28: 2149-2155, 2012.

51. Wei J, Costa C, Ding Y, Zou Z, Yu L, Sanchez JJ, Qian X, Chen H, Gimenez-Capitan A, Meng F, et al: mRNA expression of BRCA1, PIAS1, and PIAS4 and survival after second-line docetaxel in advanced gastric cancer. J Natl Cancer Inst 103: 1552-1556, 2011.

52. Hoefer J, Schäfer G, Klocker H, Erb HH, Mills IG, Hengst L, Puhr M and Culig Z: PIAS1 is increased in human prostate cancer and enhances proliferation through inhibition of $\mathrm{p} 21$. Am J Pathol 180: 2097-2107, 2012.
53. Chen Y, Li S, Li S, Li YJ, Su Y, Wong S and Zaia J: Inhibitors of deSUMOylation enzymes and methods for their use. WO Patent 2012064887 A1. Filed November 9, 2011; issued May 18, 2012.

54. Chen Y: Methods of identifying SENP1 inhibitors. US Patent 20140302525 A1. Filed April 7, 2014; issued October 9, 2014

55. Madu IG, Namanja AT, Su Y, Wong S, Li YJ and Chen Y: Identification and characterization of a new chemotype of noncovalent SENP inhibitors. ACS Chem Biol 8: 1435-1441, 2013.

56. Chen $\mathrm{CH}$, Namanja AT and Chen Y: Conformational flexibility and changes underlying activation of the SUMO-specific protease SENP1 by remote substrate binding. Nat Commun 5: 4968, 2014.

57. Madu IG, Li S, Li B, Li H, Chang T, Li YJ, Vega R, Rossi J, Yee JK, Zaia J, et al: A Novel Class of HIV-1 Antiviral Agents Targeting HIV via a SUMOylation-Dependent Mechanism. Sci Rep 5: 17808, 2015.

58. Wang LS, Sun HY, Wu ZZ, Xiao FJ, Wang H and Yang YF: SENP1 protein inhibitors and uses thereof. CN Patent 104436196 A. Filed September 23, 2013; issued March 25, 2015.

59. Zhang J, Cheng JK, Lu SY, Cheng YY, Zhang JM and Huang M: Senpl small molecule inhibitors and their applications. CN Patent 103961348 B. Filed February 5, 2013; issued August 17, 2016.

60. Chen Y, Wen D, Huang Z, Huang M, Luo Y, Liu B, Lu H, Wu Y, Peng Y and Zhang J: 2-(4-Chlorophenyl)-2-oxoethyl 4-benzamidobenzoate derivatives, a novel class of SENP1 inhibitors: Virtual screening, synthesis and biological evaluation. Bioorg Med Chem Lett 22: 6867-6870, 2012.

61. Cheng J, Kang X, Zhang S and Yeh ET: SUMO-specific protease 1 is essential for stabilization of HIFlalpha during hypoxia. Cell 131: 584-595, 2007.

62. Bawa-Khalfe T, Cheng J, Lin SH, Ittmann MM and Yeh ET: SENP1 induces prostatic intraepithelial neoplasia through multiple mechanisms. J Biol Chem 285: 25859-25866, 2010.

63. Yamaguchi T, Sharma P, Athanasiou M, Kumar A, Yamada S and Kuehn MR: Mutation of SENP1/SuPr-2 reveals an essential role for desumoylation in mouse development. Mol Cell Biol 25: 5171-5182, 2005.

64. Cheng J, Bawa T, Lee P, Gong L and Yeh ET: Role of desumoylation in the development of prostate cancer. Neoplasia 8: 667-676, 2006

65. Zhang J, Cheng JK, Huang M, Chen YY, Huang ZM, Lu SY and Shi T: SENP2 small molecule inhibitor and applications thereof CN Patent 103877078 A. Filed December 20, 2012; issued June 25, 2014.

66. Dou QP and Zonder JA: Overview of proteasome inhibitor-based anticancer therapies: Perspective on bortezomib and second generation proteasome inhibitors versus future generation inhibitors of ubiquitin-proteasome system. Curr Cancer Drug Targets 14: 517-536, 2014.

67. Chen JW, Ink BS and Lewis AP: Cysteine protease polypeptides. GB2371801, 2002.

68. Ink BS and Lewis AP: Cysteine protease polypeptide. GB2372504, 2002.

69. Chen JW, Ink BS and Lewis AP: Cysteine protease polypeptide. GB2372994, 2002

70. Ink BS: Protease polypeptide. GB2382078, 2003.

71. Góra $\mathrm{J}$ and Latajka R: Involvement of cysteine proteases in cancer. Curr Med Chem 22: 944-957, 2015.

72. Wu HJ, Liu WD, Hong YD and Guo QP: Identification of a breast cancer suppressor and methods for use. CN101923095, 2010.

73. German RA and Sangita P: Modulation of cellular protein function by artifical SUMO ligases. US Patent 20120246757 A1. Filed March 22, 2012; issued September 27, 2012. 